\title{
A teoria das Representações Sociais como referencial teórico- metodológico na pesquisa em Ensino de Biociências e Saúde
}

\section{The theory of Social Representations as theoretical and methodological framework in research in Teaching of Bioscience and Health}

\author{
${ }^{1}$ Ana Paula Inácio Diorio ana.diorio@ioc.fiocruz.br \\ ${ }^{2}$ Marco Antônio Ferreira da Costa \\ ${ }^{3}$ Gustavo Clayton Alves Santana
}

\section{RESUMO}

A teoria das Representações sociais, descrita por Serge Moscovici, tem ganhado cada vez mais espaço nos campos de pesquisa fora da psicologia social, com destaque para as áreas da saúde e do ensino. O presente estudo, de cunho qualitativo, tem como objetivo discutir o emprego dessa teoria como referencial teórico-metodológico na pesquisa em ensino de biociências e saúde. Diante dos exemplos trazidos para a discussão, através de um levantamento bibliográfico resultado de uma investigação de uma tese de doutorado em andamento , foi possível perceber que essa teoria tem sido empregada de maneira significativa na área do ensino e, principalmente, da saúde, o que indica um movimento no sentido de uma abordagem voltada para as questões relacionadas aos sujeitos e sua interação com o mundo, o grupo social e com a construção da realidade.

Palavras-chave: Representações socias, educação em saúde, ensino de ciências

\begin{abstract}
:
The theory of social representations described by Serge Moscovici has gained more and more space in the search fields outside of social psychology especially in the areas of health and education. This study of qualitative nature aims to discuss the use of this theory as theoretical and methodological research in teaching life sciences and health. On the examples brought to the discussion through a literature result of an investigation of a doctoral thesis in progress, it was revealed that this theory has been significantly used in education and especially health which indicates a move towards a focused approach to the issues related to the subjects and their interaction with the world, the social group and the construction of reality.
\end{abstract}

Keywords: social representations, health education, teaching science

1 Professora do curso de Licenciatura em Educação do Campo da Universidade Federal da Bahia (UFRB), Centro de Ciência e Tecnologia em Energia e Sustentabilidade (CETENS) e doutoranda do Programa de Pós-graduação em Ensino de Biociências e Saúde.

2 Professor do Programa de Pós-graduação em Ensino de Biociências e Saúde e pesquisador da Escola Politécnica de Saúde Joaquim Venâncio.

3 Doutorando do Programa de Pós-graduação em Sociologia Política da UENF 


\section{INTRODUÇÃO}

Diante da importância da abordagem da relação saúde/doença no ensino de ciências e consequentemente da pesquisa para a área, trazer para o campo do ensino de biociências referenciais teóricos que permitam observar o sujeito e sua totalidade e não apenas sob o absolutismo do saber científico, se mostra relevante para o debate.

Os Parâmetros Curriculares Nacionais de Ciências (PCN's) naturais sugerem que as questões de saúde sejam abordadas de forma ampla, através do eixo temático Ser Humano e Saúde, dentro do qual a discussão deve ser orientada pelas relações entre os problemas de saúde e fatores econômicos, políticos, históricos e sociais (Brasil, 1998). Nesse sentido, podemos ressaltar a contribuição dos estudos da Psicologia e das Ciências Sociais contemporâneas, das quais emerge a teoria das Representações sociais como referencial teórico- metodológico das ciências humanas, cuja função caminha no sentido do "poder de significar, de construir sentido, de criar realidade. ” (JOVCHELOVITCH, 2011, p. 35).

Em discussão acerca dos PCN’s de Ciências Naturais com ênfase no eixo temático "Ser humano e saúde", Diório e Costa (2014), destacam a dificuldade em se exercer a interdisciplinaridade proposta pelos temas transversais que contemplam os documentos oficiais. O que reafirma a importância de se (re) pensar os referenciais teóricos e metodológicos da área, tanto na reflexão acerca da prática pedagógica diária quanto nas pesquisas em ensino de biociências e saúde.

Nesse sentido, o trabalho pretende contribuir para a discussão do emprego da teoria das Representações Sociais para os estudos na área do ensino das biociências e saúde, através de exemplos do emprego da teoria na área. O levantamento bibliográfico apresentado e discutido nesse artigo faz parte do início de uma pesquisa descritiva de cunho qualitativo de doutorado em andamento a partir de projeto aprovado pelo CEP sob o parecer 331.174 de 15/07/2013, o qual se intitula "As Representações Sociais da Aids elaboradas por monitores de Escolas Famílias Agrícolas da Bahia ”. Diante disso, o trabalho seguirá o seguinte percurso: (1) a teoria das Representações Sociais (TRS), (2) a TRS e a relação saúde/doença; (3) a intercessão entre TRS e o ensino de Biociências e Saúde e (4) considerações finais. A próxima etapa da pesquisa, a qual está em andamento, consiste no levantamento de trabalhos publicados em revistas e periódicos selecionados nas áreas de saúde e de ensino sobre Representações sociais da AIDS e sua relação com o ensino de ciências.

\section{A TEORIA DAS REPRESENTAÇÕES SOCIAIS}

As representações das quais esse trabalho se ocupará, segundo os critérios moscovicianos, são vistas como um fenômeno psicossocial e estão situadas na fronteira entre os universos de pensamento, na passagem que atravessam as formas de conhecimento ao saírem dos ambientes reificados onde o pensamento se apresenta frio, duro, científico, civilizado para os ambientes consensuais onde se constituem em "verdadeiras teorias do senso comum” (MOSCOVICI, 2011, p.46).

Assentada em um alicerce teórico e metodológico transdisciplinar a teoria das Representações Sociais de Moscovici insere-se na fronteira da teoria social contemporânea.

O fato de ter chegado ao Brasil trazida por psicólogos sociais fez com que esta teoria ficasse, por algum tempo, restrita ao círculo de pesquisadores desse campo, situação que tem mudado diante do intenso intercâmbio que vem se construindo entre os que se ocupam do estudo dos fenômenos sociais assentados na contemporaneidade.

O entendimento do conceito de representação não é questão pacífica entre as mais diversas disciplinas das ciências sociais, sua onipresença nos campos de estudo acabou constituindo enorme polêmica acerca de si e seus 
significados. Diversos autores tais como: Weber, Marx, Schutz, Bakhtin, Gramsci, Lukács, Elias e Bourdieu, entre outros, trataram, cada um à sua maneira, o conceito de representações e buscaram compreender seu papel na sustentação do tecido social.

As Representações Sociais moscovicianas ganharam destaque dentro da psicologia social como referencial teórico principal nos estudos dessa natureza, porém é importante destacar que o autor Serge Moscovici, apesar de ter sido considerado o pioneiro no que diz respeito teoria em sua perspectiva psicológica, o próprio autor destaque que, do ponto de vista sociológico esse conceito chegou até ele a partir dos estudos de Durkheim (MOSCOVICI,2011).

O sociólogo Durkheim é o autor que primeiro trabalha o conceito de Representações Sociais de maneira explícita, através do termo Representações Coletivas, o qual se refere "a categorias de pensamento através das quais determinada sociedade elabora e expressa sua realidade” (MINAYO, 2012, p. 74). Estudiosos como Bohannam, Sapir, Malinowski, Kroeber e Marcel Mauss compartilham das ideias de Durkheim sobre Representações Sociais a partir da perspectiva da antropologia cultural ao abordarem questões relacionadas à consciência coletiva e a cultura.

Durkheim ao tratar das representações coletivas, a partir de vertentes sociológicas, definiu as mesmas como uma cadeia completa de formas intelectuais que incluíam ciência, religião, mito, modalidades de tempo e espaço. Para ele, fiel a tradição aristotélica e kantiana, a concepção de representações era bastante estática, além disso a formulação do conceito feita, por carregar um esforço em estabelecer a sociologia como ciência autônoma, o levou a defender a separação radical entre representações individuais e coletivas, sendo que, as primeiras seriam campo da psicologia enquanto as últimas constituiriam o objeto da sociologia (MOSCOVICI, 2011).

Minayo (2012) aborda como o papel das Representações Sociais pode ser interpretado a partir da dialética marxista, já que, para Marx a manifestação da consciência se faz através da linguagem. E que, a partir dessa leitura os marxistas Gramsci e Lukács se aprofundam mais no campo das representações sociais quando o primeiro trata do senso comum e do bom senso. A autora destaca ainda que estudiosos como Bourdieu e Bakhtlin também se ocupam das Representações Sociais através da valorização da fala como expressão das condições de existência.

Definidas nas ciências sociais como ideias, ou categorias de pensamento que servem para expressar a realidade, em muitos momentos lhe explicando, em outros lhe justificando, ou até mesmo lhe questionando (MINAYO, 2012), as representações apresentam-se como uma categoria que pode romper com as características impessoais que veem o conhecimento como racionalidade pura, pois estas estando efetivamente na base de todos os sistemas de saber, de uma maneira dialógica, pois são geradas pelas inter-relações, auxiliam na sua compreensão. Esta dialogia "nos fornece a chave para entender a relação que amarra o conhecimento à pessoa, a comunidade e mundos de vida”. (JOVCHELOVITCH, 2011, p. 21).

Ao tratar das Representações Sociais enquanto formas de conhecimento SPINK (2012) as coloca a partir das correntes que estudam o conhecimento do senso comum, o que pressupõem a desconstrução da retórica da verdade intrínseca da Revolução Científica. Para a autora as Representações Sociais devem ser estudadas considerando elementos mentais, afetivos, sociais articulados com a comunicação, a cognição e a linguagem conectados às relações sociais e materiais como essas afetam as representações sociais (SPINK,2012; JODELET, 1989).

Ao tratar das atribuições das representações na sustentação dos contextos do saber, JOVCHELOVIT (2011) as compreende como estruturas mediadoras que afloram da relação sujeito-outro-objeto, parte do trabalho comunicativo cotidiano, ou seja, geradas pela ação comunicativa (Figura 1). 
Figura 1: A arquitetura da representação: constituintes e modos de produção. Adaptado de Jovchelovitch, 2011.

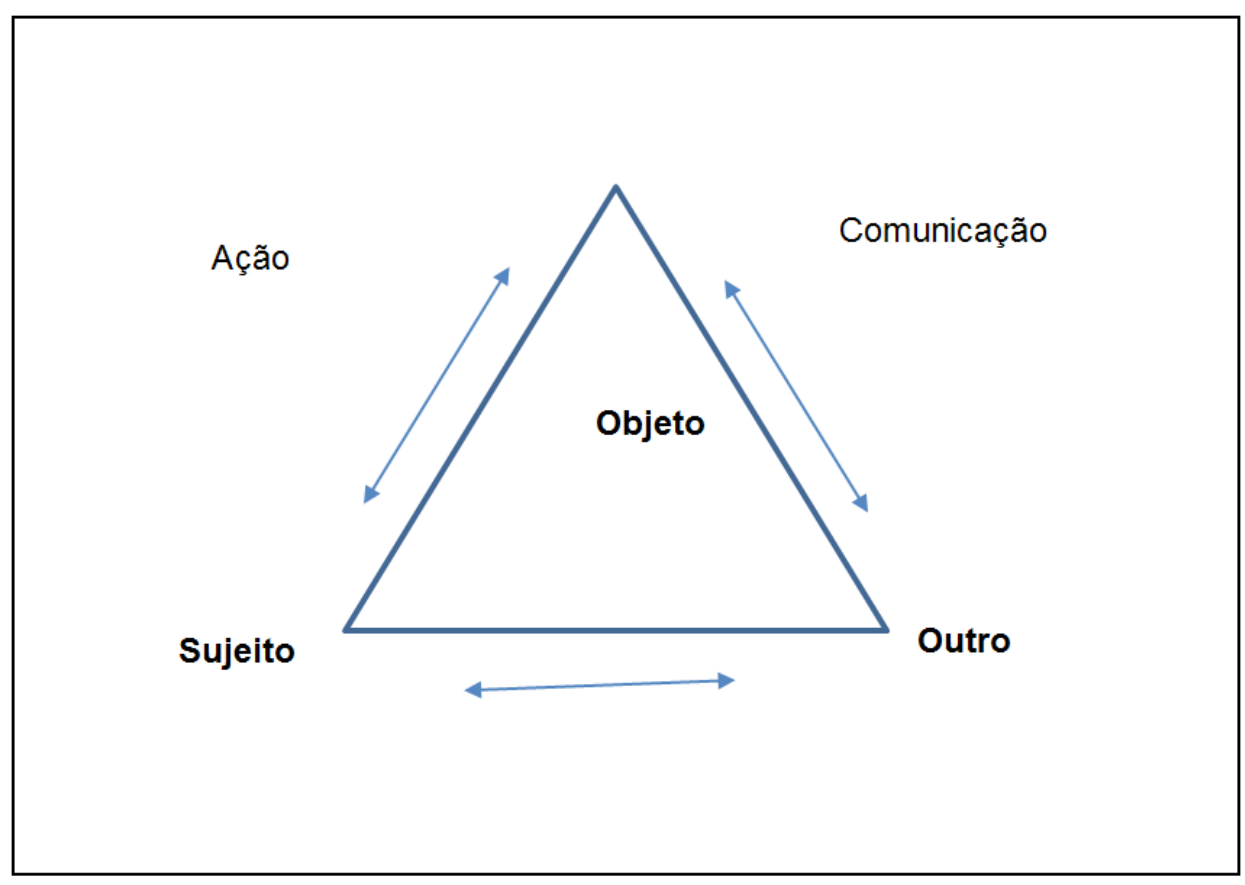

O dinamismo da vida social requer dos sujeitos uma constante tomada de posição frente ao cotidiano, é o preço que se paga por estar inserido em um grupo social. Trata-se de construir, consolidar e transmitir visões de mundo e para dar cabo a esta tarefa sujeitos e grupos sociais utilizam-se das representações.

Representar, nos recorda Jovchelovitch (2011), é propriamente o ato de dar forma, de tornar presente o que está ausente, o conceito de representação "está na base da inclusão e da exclusão - quem é e quem não é representado? - no centro do nosso conhecimento sobre nós mesmos e sobre o mundo em que vivemos". (JOVCHELOVITCH, 2011, p. 33).

Oliveira e Werba (2012, p.105) tratam as Representações Sociais como ““teorias” sobre saberes populares e do senso comum, elaboradas e partilhadas coletivamente, com finalidade de construir e interpretar o real”. Para os autores a importância no estudo das RS está na tentativa de "buscar conhecer o modo de como um grupo humano constrói um conjunto de saberes que expressam a identidade de um grupo social” (OLIVEIRA E WERBA 2012, p.107) e de seus códigos culturais ao longo do tempo.

As representações são, antes de tudo, um processo de disputa, um sistema que é construído no decurso da ação social dos sujeitos e seus grupos. "Elas implicam um trabalho simbólico que emerge das inter-relações Eu, outro e objeto-mundo e, como tal, têm o poder de significar, de construir sentido, de criar realidade. " (JOVCHELOVITCH, 2011, p. 35).

Diretamente associadas à teia de relações estabelecida entre os sujeitos, seus pares e o mundo as representações são, efetivamente, sociais e precisam ampliar as fronteiras da psicologia social. Tarefa à qual se incumbiu Serge Moscovici ao formular sua Teoria das Representações Sociais, inicialmente apresentada com a publicação do estudo La Psychanalyse: Son image et son public de 1961.

As representações sociais possuem uma intima relação com a formação do saber praticado pelos sujeitos sociais e seus grupos no decurso da vida em sociedade. Como fenômenos que necessitam ser descritos e explicados, as representações sociais de Moscovici estão relacionadas com um modo particular de compreender e de 
se comunicar - um modo que cria tanto a realidade como o senso comum. É para enfatizar esta distinção que ele usa o termo "social" em vez de "coletivo".

A proposta de Moscovici é considerar como um fenômeno o que antes era um conceito (na visão clássica de Durkheim, as representações eram coletivas, fatos sociais, em Moscovici elas adquirem uma nova conotação) para isso:

As representações sociais devem ser vistas como uma maneira específica de compreender e comunicar algo que já sabemos. Elas ocupam, com efeito, uma posição curiosa, em algum ponto entre conceitos, que têm como seu objetivo abstrair sentido do mundo e introduzir nele ordem e percepções, que reproduzam o mundo de uma forma significativa. Elas sempre possuem duas faces, que são interdependentes, como as duas faces de uma folha de papel, a face simbólica e a face icônica. Nós sabemos que representação = imagem/significação; em outras palavras, a representação iguala toda imagem a uma ideia e toda ideia a uma imagem (MOSCOVICI, 2011, p. 46).

Para Moscovici (2011 p. 54) “a finalidade de todas as representações é tornar familiar algo não familiar, ou a própria não familiaridade”. Ou seja, há um universo consensual no qual o conflito é evitado, as crenças são confirmadas, as novas interpretações de mundo têm maior poder de reafirmar as tradições do que negá-las, nesse sentido "a dinâmica das relações é uma dinâmica de familiarização, onde os objetos, pessoas e acontecimentos são percebidos e compreendidos em relação a prévios encontros e paradigmas” (MOSCOVICI, 2011 p. 55).

Para transformar o novo, o desconhecimento em usual, ou seja, o não familiar em familiar, Moscovici (2011) argumenta que dois mecanismos devem ser colocados em ação: a ancoragem e a objetivação. O primeiro mecanismo diz respeito a tentativa de ancorar ideias estranhas em categorias e imagens comuns, trazendo-as para um contexto familiar e o segundo mecanismo é transformar algo abstrato em algo quase concreto, transferir o que está na mente para o mundo físico, objetivá-los.

Portanto “ancorar é, pois, classificar e dar nome a alguma coisa”. O processo de ancoragem é aquele "que transforma algo estranho e perturbador, que nos intriga em nosso sistema particular de categorias e o campara com um paradigma de uma categoria que nós pensamos ser apropriada” (MOSCOVICI, 2011 p. 61).

Já a objetivação "é um processo muito mais atuante que a ancoragem”, ela "une a ideia de não familiaridade com a de realidade, tornar-se a verdadeira essência da realidade” [...] "a objetivação aparece, então, diante dos nossos olhos, física e acessível. Sendo assim, "objetivar é descobrir a qualidade icônica de uma ideia; é reproduzir um conceito em uma imagem” (MOSCOVICI, 2011 p. 71).

\section{A TEORIA DAS REPRESENTAÇÕES SOCIAIS NA RELAÇÃO SAÚDE/DOENÇA}

Muitos trabalhos já foram desenvolvidos no campo da saúde/doença a exemplo de Jodelet (1989); Herzlich (1991); Sevalho (1993) e autores que tratam especificamente do caso da Aids, como Joffe (1994), Spink (1992:2001), Tura (1997), Giacomozzi e Camargo (2004), Camargo (2007), entre outros), no que diz respeito à tentativa de compreensão das representações sociais de algumas doenças e seus desdobramentos nos campos: sócio-histórico, da psicologia e da antropologia. Agregando ainda mais conhecimento e compreensão à área médica e da saúde coletiva, no que diz respeito ao sujeito em sua totalidade e não apensas sob o absolutismo do saber científico.

Além disso, a teoria também ganha força no discurso da educação em saúde como argumenta Gazzinelli et al (2005) e outros autores que serão discutidos ao longo desse trabalho. 
No que diz respeito às representações sociais da saúde e da doença Gomes, Mendonça e Pontes (2002, p.2) acreditam que a partir desse debate as ações em saúde coletiva possam dar continuidade ao seu repensar para contemplar, visto que ele é oriundo da reflexão e das práticas sociológica e antropológica, além de comtemplar as dimensões social e individual da doença, "refletidas nas permanências culturais das representações e presentes nas experiências individuais que ocorrem no processo de adoecer”.

Sendo assim, o olhar sob o corpo adoecido apenas pela ótica da medicina e da tentativa de cura e/ou amenização do sofrimento e da dor não são capazes de dar conta da complexidade do sujeito, suas experiências de vida e muito menos de suas representações sobre a doença que se abateu sobre seu estado de saúde, a qual é capaz de alterar também sua percepção de mundo e de lugar no grupo social. E por isso os esforços da pesquisa na área devem acontecer no sentido de afastar a dicotomia entre representações e práticas, corpo e mente, indivíduo e sociedade, subjetividade e objetividade.

A fim de não reproduzir esses afastamentos Alves e Rabelo (1998, p.113) primam pelo deslocamento da doença "como fato (seja dado empírico ou signo) para o curso da doença como experiência". Visto que, as representações não são sistemas fechados, mas em constante transformação.

\section{INTERCESSÃO ENTRE TEORIA DAS REPRESENTAÇÕES SOCIAIS E O ENSINO DE BIOCIÊNCIAS E SAÚDE}

A fim de trazer a teoria das representações sociais para o diálogo com a pesquisa em ensino de biociências e saúde, esse trabalho é resultado de um levantamento de artigos ${ }^{4}$, que dialogam com o emprego da teoria como referencial teórico-metodológico para a pesquisa em ensino de biociências e saúde, realizado para compor o referencial teórico de uma pesquisa de doutorado em andamento intitulada: "As Representações Sociais da Aids elaboradas por monitores de Escolas Agrícolas da Bahia”. Nesse sentido, os artigos serão apresentados dentro da discussão, já que o objetivo do trabalho era travar o diálogo e não realizar um levantamento numérico.

A teoria das representações sociais ganhou espaço e relevância na psicologia social, nas ciências sociais e nos estudos no campo da saúde, por conta de sua tentativa de aproximação entre sujeito - objeto, quanto busca entender a construção da realidade que esses sujeitos fazem ao interpretar o mundo. Diante disso e aliado à necessidade crescente das investigações em ensino de biociências e saúde dialogarem com os referenciais teóricos-metodológicos da Psicologia e das Ciências Sociais contemporâneas, a tentativa de compreensão de questões relacionadas aos sujeitos imersos nesse contexto da educação formal e não formal se faz necessário para responder as demandas e as lacunas que ainda existem nesse campo de pesquisa.

Dentre alguns enfoques de pesquisa que consideram a TRS no âmbito do Ensino das Biociências, podem ser destacados, por exemplo: a produção de Schaffer (2007) sobre a polissemia do termo "orgânico”, com alunos universitários; o trabalho de Silva \& Pitombo (2006) sobre as RS de "queima” e "combustão", com educandos do ensino básico; a investigação de Cortes Jr., Corio \& Fernandez (2009), que analisou o que alunos universitários representavam sobre "química ambiental"; o estudo de Mazzotti (1997) sobre as RS de "problema ambiental”, envolvendo professores, alunos, documentos e livros didáticos; a pesquisa de Magalhães Jr. \& Tomanik (2012) sobre educação ambiental, com alunos do ensino básico; a investigação de Hilger (2011) sobre as RS da física quântica apresentadas por estudantes do ensino médio; o trabalho de Melo, Tenório \& Accioly Jr. (2010) sobre as RS de licenciandos de Física sobre a ciência; a produção de Valença \& Falcão (2012), que descreveu as RS de professores de Biologia sobre a teoria da evolução e ainda o trabalho Fonseca e Loguercio (2013) sobre as representações sociais da nutrição para a produção de um material didático de química.

4 A busca de seu, basicamente, nas bases de dados "Scientific Eletronic Library Online" (SciELO) e INDEXPSI no período de junho a novembro de 2014. 
Os pesquisadores Martinho e Talamoni (2007) se debruçaram na tentativa de compreender as representações sociais de alunos da quarta série do ensino fundamental em duas escolas públicas no interior paulista, revelando representações antropocêntricas e naturalistas. O que os autores acreditam contribuir para que os professores, ao considerarem os saberes, vivências e experiências dos alunos possam desenvolver ações educativas comprometidas com uma prática pedagógica ambientalmente crítica.

Lacolla (2005), afirma que quando nos apropriamos das Representações Sociais podemos entender a maneira pela qual as concepções carregadas de sentidos se formam no pensamento dos alunos e incidem na construção dos conceitos que trabalhamos em nossas classes. Para a autora, que é professora na área de ciências naturais, tomar contato com uma teoria de origem sociológica, como é o caso das Representações Sociais, nos permite interpretar os estudos associados aos conhecimentos "ingênuos" e "espontâneos" dos alunos, suas concepções previas ou preconcepções.

Para Gazzinelli et all (2005), para pensar Educação e Saúde é preciso levar em conta as representações dos sujeitos, as quais podem ser entendidas como noções e modos de pensamento construídos ao lado de suas trajetórias de vida cuja experiência coletiva, os fragmentos das teorias científicas e dos saberes escolares, expressos, também, nas práticas sociais e modificados para servir à vida cotidiana.

Em pesquisa realizada com 24 adolescentes da cidade de Vitoria da Conquista, na Bahia, Silva et al (2014, p.2) investigou as representações sociais sobre ser saudável desses jovens. Evidenciando a importância da teoria no deslocamento das questões ligadas à saúde dos adolescentes, as quais têm sido em sua maioria, interpretadas a luz do "paradigma biomédico, enfocando a adolescência como um fenômeno natural, universal, pautado num paradigma a-histórico e que não considera o contexto em que esse indivíduo está inserido”.

Camargo et al. (2009), também encontrou na teoria das representações sociais um meio de compreender as representações dos adolescentes, estudantes de uma escola estadual de Florianópolis, acerca da doença Aids e as estimações deles das representações de outros adolescentes. O resultado da pesquisa revelou uma representação da Aids como problema social, biomédico e relacionado a intimidade, o que pode facilitar a compreensão de pesquisados a acerca do fenômeno e como ele é representado pelos jovens, que hoje, são os que apresentam a maior taxa de contaminação pelo vírus HIV.

Nesse sentido, tais estudos podem ser relevantes para se pensar as políticas públicas em saúde com foco nesse público, atendendo suas especificidades a partir da leitura de suas maneiras particulares de ver o mundo, as quais têm na escola um importante espaço de construção e por isso um espaço, também, de reflexão, reconstrução das representações sociais, já que é nesse ambiente que o saber científico é reificado, objetivado e ancorado na tentativa do sujeito de tornar o não- familiar em familiar, compartilhando essas construções individuais com o grupo social.

Considerar o ensino de biociências e saúde na perspectiva das representações sociais é compreender que os processos de ancoragem e objetivação influenciam, tanto na forma de ser e estar no mundo, já que são eles que transformam aquilo que é estranho em familiar, quanto nos processos de ensino e aprendizagem. Visto que os últimos precisam ser considerados a partir do sujeito e sua inserção no mundo.

O que acreditamos contribuir para o exercício de uma pedagogia problematizadora, assim como defendida por Freire (1987), a qual proporciona uma relação dialógica-dialética, já que o educador e educando integram um mesmo processo, na qual ambos aprendem juntos. Logo, pensar a partir das representações sociais é também considerar os sujeitos e dialogar com os saberes construídos pelos grupos sociais e assim promover o diálogo, a aproximação, a troca de informações, educador e educando interagem saberes e produzem conhecimento. 


\section{CONSIDERAÇÕES FINAIS}

A reflexão apresentada pode trazer elementos para ampliar a discussão no campo do Ensino em Biociências e Saúde, no que diz respeito a aproximação e importância das teorias sociológicas para as pesquisas na área. E nesse sentido, pensar o ensino de ciências a partir do sujeito e de suas impressões do mundo e do grupo social no qual está inserido.

O diálogo entre o referencial teórico-metodológico da Teoria Representações Sociais e a pesquisa em ensino está posto e isso pôde ser visto nas pesquisas apresentada nesse estudo. O campo da saúde vem ganhando expressividade na área da enfermagem e da psicologia social e recentemente do ensino e educação, visto a necessidade de um diálogo voltado para a amplitude e complexidade do indivíduo e da relação saúde/doença, que não cabem apenas no saber médico, biológico e às vezes fechado em uma visão científica do corpo, processo de adoecimento, tratamento e prevenção que nem sempre levam em conta as formulações que os sujeitos fazem da própria realidade.

Sendo assim, pensar o ensino de biociências e saúde a partir das Ciências Sociais contemporâneas e da Psicologia, assim como sugere os PCN's, pode ser um caminho a seguir na busca da compreensão e da formulação dos fenômenos científicos a partir das teorias do senso comum e diante dela pensar as melhores maneiras para dialogar com os alunos, tomando a escola como um espaço privilegiado para a investigação e compreensão das representações sociais. 


\section{REFERÊNCIAS}

ALVES, P. C. RABELO, M. C., 1998. Repensando os estudos sobre representações e práticas em saúde/doença. In: Antropologia da Saúde: Traçando Identidades e Explorando Fronteiras (P. C. Alves \& M. C. Rabelo, org.), pp. 107-121, Rio de Janeiro: Editora Fiocruz/Relume Dumará.

BARBARÁ, A. SACHETTI, V.A.R. CREPALDI, M. A. Contribuições das representações sociais ao estudo da Aids. Interação em Psicologia, 2005, 9(2), p. 331-339.

BARDIN, L. Análise de Conteúdo. $4^{\mathrm{a}}$ Ed. Edições 70, 2010.

BRASIL. Ministério da Saúde. Departamento de DST, Aids e Hepatites Virais. Boletim Epidemiológico Aids e DST, Brasília, 2011, 2012.

CAMARGO, B.V. Barbará, A. Bertoldo, R.B. Concepção pragmática e científica dos adolescentes sobre a Aids. Psicologia em Estudo. V. 12, n. 2, p. 277-284, 2007.

Representações sociais da AIDS e alteridade. Estudos e pesquisas em Psicologia, Ano 9, N.3, p. 710-723, 2009.

CORTES Jr. L. P. CORIO, P., \& FERNANDEZ, C. As representações sociais de química ambiental dos alunos iniciantes na graduação em Química. Química Nova na Escola, 31(1), 46-54, 2009.

DIÓRIO, A.P; COSTA, M.A.F. Parâmetros Curriculares de Ciências Naturais: a questão da interdisciplinaridade e da transversalidade no Ensino de Ciências. Anais do IV Encontro Nacional de Ensino de Ciências da Saúde e do Ambiente, 2014. Disponível em:http://www.ivenecienciassubmissao.uff.br/ index.php/ivenecienciassubmissao

FERREIRA, S.R.S; BRUM, J.L.R. As representações sociais e suas contribuições no campo da saúde. Revista Gaúcha de Enfermagem, v.20, n.esp., p. 5-14, 2000.

FONSECA, V.C. LOGUERCIO, R, Q. Representações sociais da nutrição: proposta de produção de material didático de química. Investigações em Ensino de Ciências - V18(2), pp. 407-437, 2013

FREIRE, Paulo. Pedagogia do Oprimido, Rio de Janeiro: Paz e Terra, 1987

GAZELLI, M.F. GAZELLI, A. REIS, D. C dos. PENNA,C. M..M. Educação em saúde: conhecimentos, representações sociais e experiências da doença. Caderno de Saúde Pública, 21(1):200-206,2005.

GIACOMOZZI, A.I. CAMARGO, B. V. Eu confio no meu marido: estudo da representação social de mulheres com parceiro fixo sobre prevenção da AIDS. Psicologia: Teoria e Prática, 6(1): 31-44, 2004.

GOMES, R.; MENDONÇA, E. A. \& PONTES, M. L. Cad. Saúde Pública, Rio de Janeiro, 18(5):1207-1214, 2002

HERZLICH, C. A Problemática da Representação Social e sua Utilidade no Campo da Doença. Revista de Saúde Coletiva. Vol. 1.1, n. 2, Rio de Janeiro, 1991.

HILGER, T. R. A física quântica como geradora de representações sociais no ensino médio. In: X Congresso Nacional de Educação EDUCERE e I Seminário Internacional de Representações Sociais, Subjetividade e Educação SIRSSE. Anais do X Educere e I SIRSSE. Curitiba, 2001

JODELET, D. Folies et Représentations Sociales. Paris: PUF, 1989. 
JOFFE, H. "Eu não”, “o meu grupo não”: representações sociais transculturais da Aids. In: GUARESCHI, P.; JOVCHELOVITCH , S. Textos em Representações Sociais. Petrópolis: Vozes, 2012. p. 239-261.

JOVCHELOVITCH, S. Os contextos do saber: representações, comunidade e cultura. 2a . ed. Petrópolis: Vozes, 2011.

LACOLLA, L. Representaciones sociales: una manera de entender las ideas de nuestros alumnos. Revista ieRed: Revista Electrónica de la Red de Investigación Educativa . Vol.1, No.3, 2005.

MAGALHÃES Jr., C. A. de O., \& Tomanik, E. A. Representações sociais e direcionamento para a educação ambiental na reserva biológica das perobas, Paraná. Investigações em Ensino de Ciências, 17(1), 227-248, 2012.

MARTINHO, L. R; TALAMONIA, J.L.B. Representações sobre meio ambiente de alunos da quarta série do ensino fundamental. Ciência \& Educação, v. 13, n. 1, p. 1-13, 2007

MAZZOTTI, T. B. Representação social de "problema ambiental”: uma contribuição à educação ambiental. Revista Brasileira de Estudos Pedagógicos, 78(188-189-190), 86-123, 1997.

MELO, E. G. S., Tenório, A., \& Accioly Jr., H. Representações sociais de ciência de um grupo de licenciandos em Física. Revista Electrónica de Enseñanza de las Ciencias, 9(2), 457-466, 2010.

MINAYO, M. C. D. S. O Conceito de Representações Sociais dentro da Sociologia Clássica. In: GUARESCHI, P.; JOVCHELOVITCH , S. Textos em Representações Sociais. Petrópolis: Vozes, 2012. p. 73-92.

MOSCOVICI, S. Representações Sociais: investigações em psicologia social. Petrópolis: Vozes, 2011.

SCHAFFER, D. Z. Representações sociais de alunos universitários sobre o termo "ORGÂNICO”. Dissertação de Mestrado, Instituto de Física, Instituto de Química, Instituto de Biociências, Faculdade de Educação, Universidade de São Paulo, São Paulo, 2007.

SEVALHO, G. A Historical Approach to Social Representations of Health and Disease. Cad.Saúde Públ., Rio de Janeiro, 9 (3): 349-363, 1993.

SILVA, A. C. S. SALES, Z.N. MOREIRA, R.M. BOERY, E.M. TEIXEIRA, J.R.B. BOERY, R.N.S DE O. Representações sociais sobre ser saudável de adolescentes escolares. Adolesc. Saude, Rio de Janeiro, v. 11, n. 1, p. 24-31, 2014

SPINK, M.J.P. et al. A construção da Aids-notícia. Caderno de Saúde Pública, 17(4):851-862, 2001.

SPINK, M.J.P. A construção social do saber sobre saúde e doença: uma perspectiva psicossocial. Saúde e Sociedade, 1 (2), 125-139, 1992.

TURA, L.F.R. Os jovens e a prevenção da Aids no Rio de Janeiro. Rio de Janeiro: Faculdade de Medicina da Universidade Federal do Rio de Janeiro (Tese de doutorado), 1997.

VALENÇA, C. R., \& Falcão, E. B. M.. Teoria da evolução: representações de professores pesquisadores de biologia e suas relações com o ensino médio. Revista Electrónica de Enseñanza de las Ciencias, 11(2), 471486, 2012, 